Karel KOLÁR $\check{R}^{1,2^{*}}$, Rafael DOLEŽAL ${ }^{1}$, Natálie KARÁSKOVÁ ${ }^{1}$

Nadezhda V. MALTSEVSKAYA ${ }^{3}$ and Š́rka KŘ́Ǐ̌KOVÁ ${ }^{4}$

\title{
MOLECULAR MODELS IN CHEMISTRY EDUCATION AT UNIVERSITY AND UPPER SECONDARY SCHOOL - STRUCTURE OF AMIDES
}

\author{
MODELE MOLEKULARNE W NAUCZANIU CHEMII \\ W SZKOLE ŚREDNIEJ I WYŻSZEJ - STRUKTURA AMIDÓW
}

\begin{abstract}
Molecular models derived from results of quantum-chemical calculations present an important category of didactic instruments in chemistry education in upper secondary school and, particularly, at university. These models can be used especially as tools for supporting the students' understanding by visual learning, which can adequately address complexity of many chemical topics, incorporate appropriate didactic principles, as well as utilize the benefits brought up by the actual information technology. The proposed molecular models are non-trivial examples of didactic application of computational chemistry techniques in illustration of electron interactions in amidic group, namely the interaction of the free electron pair on the nitrogen atom with the carbonyl group and also the interaction of atoms in the amide group with other surrounding atoms in the molecule. By these molecular models it is possible to explain acid-base properties of amides applying knowledge of electron density distribution in the molecules and the resulting electrostatic potential. Presentation of the structure and properties of the amides within education is important also for the reason that amidic functions are involved in many important natural substances (e.g. proteins, peptides, nucleic acids or alkaloids), synthetic macromolecular substances (e.g. Silon) or pharmaceutical preparations (e.g. paracetamol). Molecular models then serve to support better understanding of the structure of these substances and, in relation to it, their properties.
\end{abstract}

Keywords: acidity, amides, basicity, electrostatic potential, molecular models

\section{Introduction}

Carboxylic acid amides belong to so-called functional carboxylic acid derivatives. These are important compounds that have specific physical, chemical and biological properties due to the polar amide group. Amides include many natural substances (proteins, peptides, some alkaloids) as well as industrial products (synthetic polyamides - Silon,

\footnotetext{
${ }^{1}$ Department of Chemistry, Faculty of Sciences, University of Hradec Kralove, Rokitanskeho 62, 50003 Hradec Králové, Czech Republic

${ }^{2}$ Department of Chemistry and Chemical Education, Faculty of Education, Charles University, M.D. Rettigove 4, 11639 Prague, Czech Republic

${ }^{3}$ State Budget Professional Education Institution, Kosygina 17(3), 119334 Moscow, Russia

${ }^{4}$ Department of Information Technologies, Faculty of Informatics and Management, University of Hradec Kralove, Rokitanskeho 62, 50003 Hradec Králové, Czech Republic

*Corresponding author: karel.kolar@uhk.cz
} 
pharmaceuticals - paracetamol) [1]. A typical feature of amide group is the interaction between the amino group and the carbonyl group, where the first group acts as an electron donor, and the second group as an electron acceptor. The interactions can be represented by the boundary resonance structures (Fig. 1).
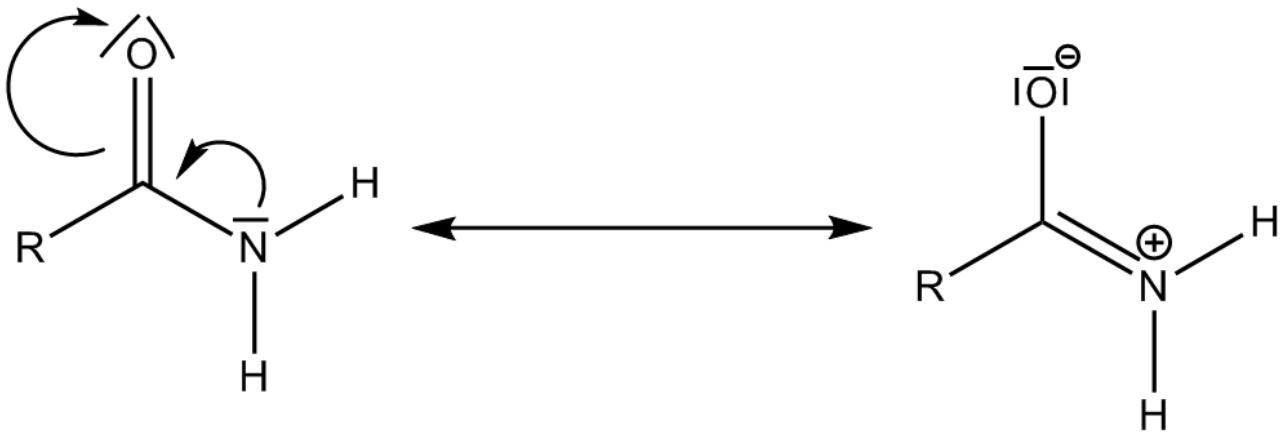

Fig. 1. Resonance structures of terminal amide group

This very important electronic interaction is related to the character of the $-\mathrm{NH}_{2}$ group as a strong electron donor and the $\mathrm{C}=\mathrm{O}$ group as a significant electron acceptor [2]. If the skeletal or electron formulas are used to represent the structure of the amides, the respective interactions can be demonstrated using the arrows. It can be seen from the formulas that the interaction is associated with a change in the electron density distribution in the molecule. This change is reflected, for example, in planar geometry of the amidic group or in the acid-base properties of amides, which can be illustrated by suitably chosen model series of compounds including amides but also other compounds [3]. Acid-base properties can be simply judged on the basis of a qualitative theory of reactivity based on application of substitution effects [4]. Nevertheless, the nature of the amide group is still relatively difficult to assess, as this group may exhibit both base and acid properties under certain conditions [5]. We therefore present another means of illustrating the presentation of amide structure - molecular models that can contribute to a certain extent to the understanding of their properties.

\section{Theoretical background}

Molecular models are constructed on the basis of quantum-chemical computations that explicitly describe the distribution of electrons in molecular systems [6]. From the point of view of chemical structure presentation, these models are beneficial in that they show, in addition to the size and shape of the molecule, a certain property - namely, the electrostatic potential (ESP), expressed in a colour gradient scale ranging from red to blue [7]. The red colour indicates regions with very negative ESP values, blue coloured area is instead a symbol of places with high positive ESP. The red ESP region in the molecule is closely related to high electron density, which, for example, attracts proton well, while the blue region in the molecule is associated with low electron density that attracts protons by a weaker strength [8].

There are a number of computational methods available to create molecular models (e.g. semiempirical methods, ab-initio methods, electron density function theory) [9]. In our study, PM6 semiempirical method implemented in the Spartan 16 program was preferred 
because of its simplicity and speed. Importantly, the PM6 method has provided also the optimal results for the studied compounds compared to other semiempirical methods (e.g. AM1 and RM1) in terms of correlation of the predicted acid-base properties with experimentally determined values of $\mathrm{p} K_{\mathrm{a}}[10]$. In order to evaluate the structure-properties relationships of the selected chemical compounds, especially their acid-base properties, the following computational outputs were investigated:

1) isodensity molecular models of amides and other compounds,

2) combined models of amides and other compounds (e.g., isodensity molecular model + ball-and-stick model),

3) electrostatic potential (ESP) values on the nitrogen atom of the amides and other compounds,

4) electrostatic potential (ESP) values on the hydrogen atom of the amides and other compounds.

These outputs allow an accurate assessment of the acid-base properties of the model compounds in combination with approaches based on the qualitative theory of reactivity $[11,12]$.

\section{Experimental part}

In order to illustrate pedagogical potential of molecular modelling by which the acid-base properties of the amides can easily be demonstrated, the following model series of compounds were proposed and analyzed [13, 14]:

1) ammonia, acetamide, acetimide,

2) acetamide, $\mathrm{N}$-methylacetamide, $\mathrm{N}, \mathrm{N}$-dimethylacetamide,

3) pyrrolidine, pyrrolidin-2-one, succinimide.

Computational models of these chemical compounds were geometrically optimized and then ESP on isodensity surface of electron density of $0.002 \mathrm{e} / \mathrm{b}^{3}$ was calculated. The differences in acidity and basicity of the studied compounds were demonstrated semi-quantitatively on the basis of differences in the colour intensity of individual atoms in the molecular models and quantitatively by determination of the electrostatic potential (ESP) values on the nitrogen and hydrogen atoms in the amidic function [12]. In the model series: 1) ammonia, acetamide, acetimide the electrostatic potential on the nitrogen atom decreases from ammonia to acetimide. The electrostatic potential on the hydrogen atom increases in the same way from ammonia to acetimide, which is reflected by an adequate colour change in the models (Fig. 2). In the model series: 2) acetamide, $\mathrm{N}$-methylacetamide, N,N-dimethylacetamide, the electrostatic potential on the nitrogen atom increases proportionally with the number of methyl groups bound to the nitrogen atom while the ESP on the hydrogen atom changes in reverse order (Fig. 3). In the model series: 3) pyrrolidine, pyrrolidin-2-one, succinimide, again, the electrostatic potential decreases on the nitrogen atom and grows on the hydrogen atom depending on the number of oxygen atoms in the molecule (Fig. 4). The ESP on the nitrogen and hydrogen atoms can be simply expressed by appropriate colour change in the molecular models. 
<smiles>N</smiles><smiles>CC(N)=O</smiles><smiles>CC(=O)NC(C)=O</smiles>
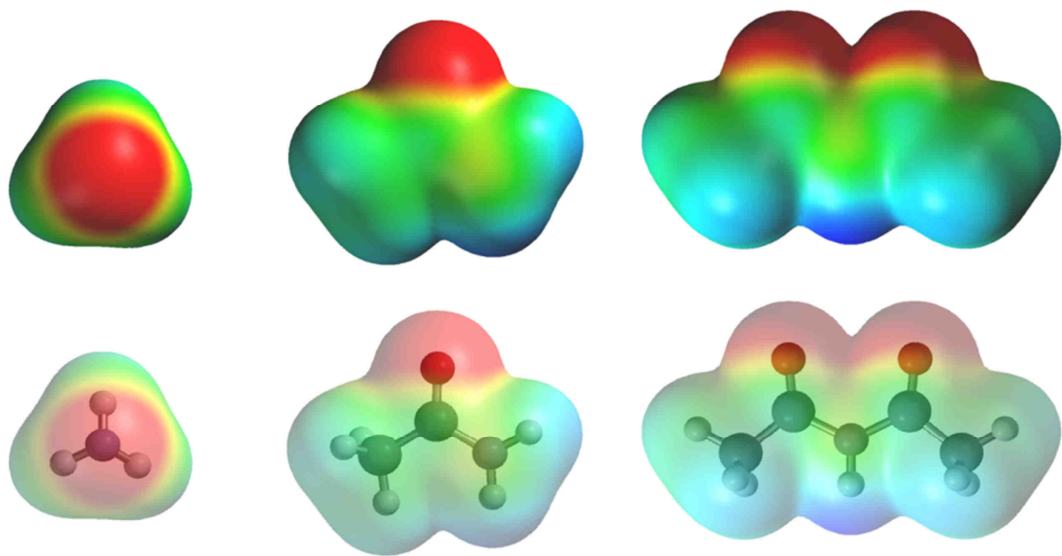

2

3

Fig. 2. Molecular models of ammonia (1), acetamide (2), acetimide (3)<smiles>CC(N)=O</smiles><smiles>CNC(C)=O</smiles><smiles>CC(=O)N(C)C</smiles>
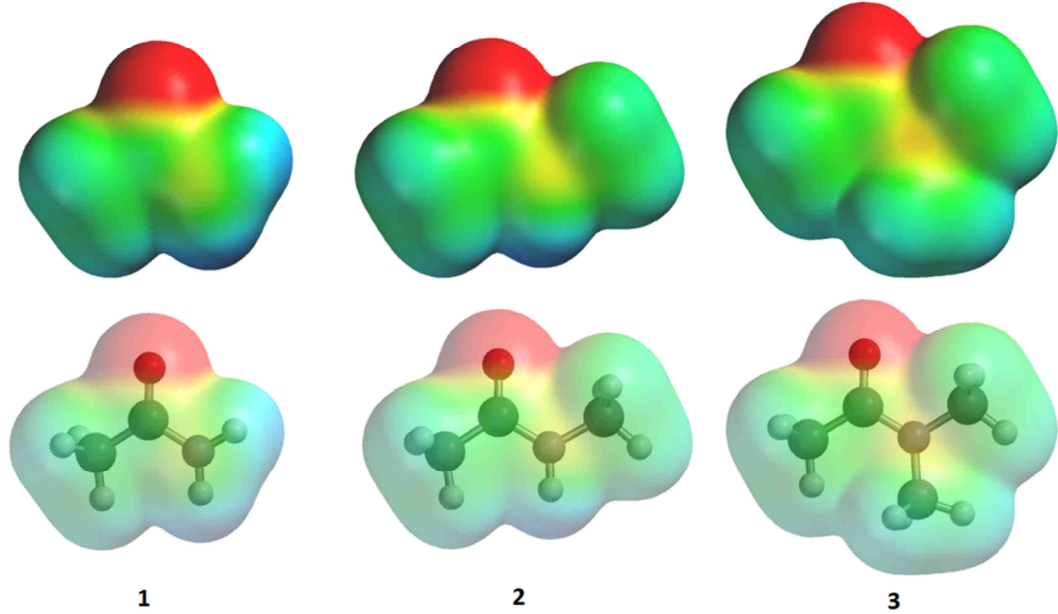

1

2

Fig. 3. Molecular models of acetamide (1), N-methylacetamide (2), N, N-dimethylacetamide (3) 


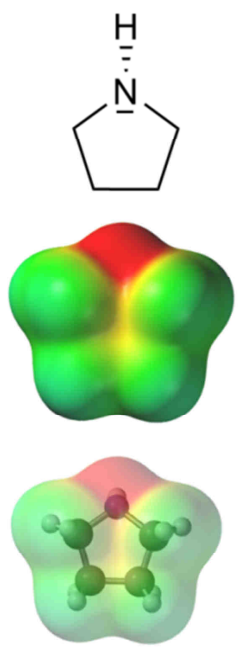

1
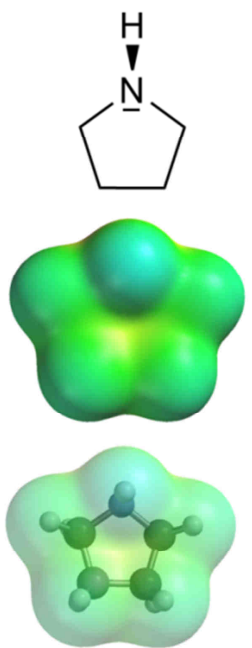

1
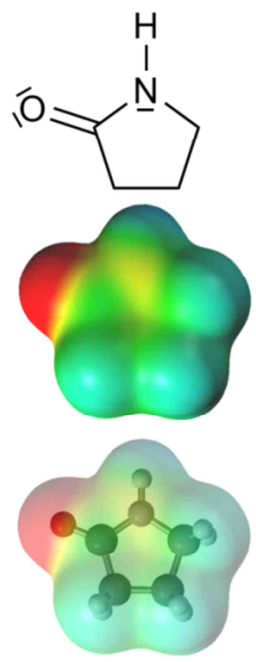

2
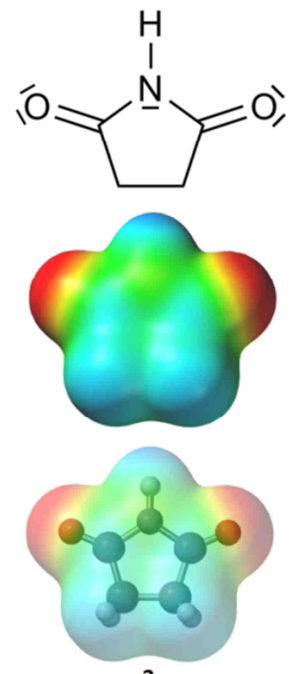

3

Fig. 4. Molecular models of pyrrolidine (1; rotated models by $180^{\circ}$ ), pyrrolidin-2-one (2), succinimide (3)

\section{Discussion}

In the study of the following models: 1) ammonia-acetamide-acetimide it was found that the nitrogen atom was red in ammonia. In acetamide and acetimide the nitrogen atoms are yellowish-green. In this series, the blue colour of the hydrogen atom deepens from ammonia to acetimide (blue-green, blue, dark blue). The electrostatic potential of the nitrogen atom decreases in the following order: $-292.6 ;-48.7 ;-32.4 \mathrm{~kJ} / \mathrm{mol}$. Similarly, the electrostatic potential of the hydrogen atom in the series increases: $73.3 ; 139.8$; $177.6 \mathrm{~kJ} / \mathrm{mol}$. From the analysis of colour changes and changes in ESP on the nitrogen and hydrogen atoms, it is clear that the basicity of the compounds decreases and the acidity increases due to the interaction of free electron pair on the nitrogen atom with one (e.g. acetamide) and then with two carbonyl groups (e.g. acetimide).

Models in the series: 2) Acetamide - N-methylacetamide - N, N-dimethylacetamide exhibit slight colour changes on the nitrogen atom as well. In acetamide, it is yellow-green, $\mathrm{N}$-methylacetamide yellow and $\mathrm{N}, \mathrm{N}$-dimethylacetamide orange. The hydrogen atom in acetamide and $\mathrm{N}$-methylacetamide has bluish colours. The ESP values on the nitrogen atom in the compound series grow: $-48.7 ;-67.7 ;-84.5 \mathrm{~kJ} / \mathrm{mol}$ and increase on the hydrogen atom in this order: $139.8 ; 145.6 \mathrm{~kJ} / \mathrm{mol} ; \mathrm{N}, \mathrm{N}$-dimethylacetamide does not contain hydrogen atom in the amidic function. It is interesting that the computational method used predicts an increased basicity as well as increased acidity of the amidic group of $\mathrm{N}$-methylacetamide in comparison with acetamide. These unusual results can explain the fact that both molecules show nearly the same experimental $\mathrm{p} K_{\mathrm{a}}$ values (Table 1 ). In general, the shift in basicity or acidity is due to the positive induction effect of the methyl group bound to the nitrogen atom.

With respect to the models in the series: 3) pyrrolidine-pyrrolidin-2-one-succinimide, colour changes were again identified on the models. In pyrrolidine, the nitrogen atom is 
dark red, in the pyrrolidin-2-one yellow and in the succinimide yellow-green. The hydrogen atom in the pyrrolidine molecule is coloured in light blue. The molecules of the pyrrolidin-2-one and the succinimide molecule have the hydrogen atom in blue colour. In the model series, ESP drops: $-302.0 ;-72.8 ;-13.3 \mathrm{~kJ} / \mathrm{mol}$ with respect to the nitrogen atom, whereas ESP values on the hydrogen atom have the opposite trend: $72.1 ; 116.4$; $128.3 \mathrm{~kJ} / \mathrm{mol}$. In the model series, the basicity of the nitrogen atom decreases, while the acidity of the compounds increases. The trend in acid-base properties corresponds to the interaction of the nitrogen atom with one and then two carbonyl groups, which results in a decrease in basicity and an increase in acidity of the model compounds.

Summarily, the calculated ESP values on the nitrogen and hydrogen atoms are convenient indicators of acid-base properties of the studied compounds for educational purposes, and they are also in good agreement with experimental $\mathrm{p} K_{\mathrm{a}}$ values measured in dimethylsulfoxide [15].

An overview of the calculated ESP values and the experimental $\mathrm{p} K_{\mathrm{a}}$ values is given in Table 1.

Table 1

ESP values on the nitrogen and hydrogen atoms and values $\mathrm{p} K_{\mathrm{a}}$

(in dimethylsulfoxide, DMSO) for the selected substances

\begin{tabular}{|c|c|c|c|c|c|c|c|c|c|c|c|}
\hline Substance & $\begin{array}{c}\text { ESP } \\
(\mathbf{H})\end{array}$ & $\begin{array}{c}\text { ESP } \\
(\mathbf{N})\end{array}$ & $\mathbf{p} \boldsymbol{K}_{\mathrm{a}}$ & Substance & $\begin{array}{c}\text { ESP } \\
(\mathbf{H})\end{array}$ & $\begin{array}{c}\mathbf{E S P} \\
(\mathbf{N})\end{array}$ & $\mathbf{p} \boldsymbol{K}_{\mathrm{a}}$ & Substance & $\begin{array}{c}\mathbf{E S P} \\
(\mathbf{H})\end{array}$ & $\begin{array}{c}\mathbf{E S P} \\
(\mathbf{N})\end{array}$ & $\mathbf{p} \boldsymbol{K}_{\mathrm{a}}$ \\
\hline Ammonia & 73.3 & -292.6 & 41.0 & Acetamide & 139.8 & -48.7 & 25.5 & Pyrrolidine & 72.1 & -302.0 & 44.0 \\
\hline Acetamide & 139.8 & -48.7 & 25.5 & $\mathbf{N}-$ methylacetamide & 145.6 & -67.9 & 25.9 & $\begin{array}{c}\text { Pyrrolidin-2- } \\
\text { one }\end{array}$ & 116.4 & -72.8 & 24.1 \\
\hline Acetimide & 177.6 & -32.4 & 17.9 & $\begin{array}{c}\text { N, N- } \\
\text { dimethylacetamide }\end{array}$ & - & -84.5 & $-^{\mathrm{a}}$ & Succinimide & 128.3 & -13.3 & 14.7 \\
\hline
\end{tabular}

${ }^{\mathrm{a}} \mathrm{p} K_{\mathrm{a}}$ value is not available

\section{Conclusion}

The proposed molecular models have clearly shown changes in the distribution of electron density and the corresponding ESP values in molecules of the selected substances. The semi-quantitative visual assessment, based on colour changes of the ESP gradient scale, was supplemented in addition by evaluation of the ESP data which confirms and refines the initial visual analysis. It has become evident that molecular models could sufficiently elucidate acid-base properties of amides which cannot be achieved by other chemistry education methods [16]. From the point of chemistry didactics, molecular models fill a gap in contemporary chemistry education methods which rely, in the case of acid-base properties explanation, mostly on verbal exposition of induction and mesomeric electron effect of substituents. Provided chemistry teachers have a good command of theoretical chemistry and computer skills, molecular modelling in their hand can turn into a valuable instrument for chemistry education [17]. The present study demonstrates that acid-base properties of amides depend on the resulting ESP values on the nitrogen and hydrogen atoms of the amidic functional group. In simple terms, if the ESP values are high positive (blue) and localize on hydrogen atoms, the molecule acts as a strong acid in the sense of Bronsted-Lowry theory. Accordingly, when the ESP values are very negative (red) and localize on nitrogen atoms, the molecule acts as a strong base in the same sense. Therefore, the results of the model analysis outline the pedagogical potential of molecular modelling 
which is in a good line with experimental data as well as with hypotheses that can be achieved by the analysis of constitutional (electron) formulas using the qualitative theory of reactivity.

\section{Acknowledgements}

The authors thank for financial support to Specific Research PřF UHK 2108/2018.

\section{References}

[1] Tsikolia M, Bernier UR, Wedge DE, Tabanca N, Abboud KA, Linthicum KJ. Chem Biodivers. 2019;16:e1800618. DOI: 10.1002/cbdv.201800618.

[2] Pron A, Leclerc M. Prog Polym Sci. 2013;38:1815-1831. DOI: 10.1016/j.progpolymsci.2013.08.007.

[3] Choudhary A, Gandla D, Krow GR, Raines RT. JACS. 2009; 131:7244-7246. DOI: 10.1021/ja901188y.

[4] Melen RL. Science. 2019;36:479-484. DOI: 10.1126/science.aau5105.

[5] Ahn S, Matzger AJ. JACS. 2010;132:11364-11371. DOI: 10.1021/ja105039s.

[6] Linenberger KJ, Cole RS, Sarkar S. J Chem Educat. 2011;88:962-965. DOI: 10.1021/ed100727r.

[7] Hinze SR, Williamson VM, Deslongchamps G, Shultz MJ, Williamson KC, Rapp DN. J Chem Educat. 2013;90:1275-1281. DOI: 10.1021/ed300395e.

[8] Mottishaw JD, Erck AR, Kramer JH, Sun H, Koppang M. J Chem Educat. 2015;92:1846-1852. DOI: 10.1021/ed5006344.

[9] Mierdel J, Bogner FX. Educat Sci. 2019;9(2):115. DOI: 10.3390/educsci9020115.

[10] Rezac J, Fanfrlik J, Salahub D, Hobza P. J Chem Theory Comput. 2009;5:1749-1760. DOI: $10.1021 /$ ct 9000922.

[11] Balogh GT, Gyarmati B. Nagy B, Molnár L, Keserü GM. Mol Inf. 2009;28:1148-1155. DOI: 10.1002/qsar.200960036.

[12] Gázquez JL, Franco-Pérez M, Ayers PW, Vela A. Int J Quan Chem. 2019;119: e25797. DOI: 10.1002/qua.25797.

[13] Johnson LE, Engel T. J Chem Educat. 2011;88:569-573. DOI: 10.1021/bk-2014-1180.ch006.

[14] Seybold PG, Shields GC. Comput Mol Sci. 2015;5:290-297. DOI: 10.1002/wcms.1218.

[15] Available from: https://www.chem.wisc.edu/areas/reich/pkatable/.

[16] Winfield LL, McCormack K, Shaw T. J Chem Educat. 2018;96:89-92. DOI: 10.1021/acs.jchemed.8b00145.

[17] Karolčík Š, Čipková E. Chem Didact Ecol Metrol. 2017;22(1-2):99-121. DOI: 10.1515/cdem-2017-0006. 